\title{
Hypocalcemia May Not Be Essential for the Development of Secondary Hyperparathyroidism in Chronic Renal Failure
}

Silvia Lopez-Hilker, Tilde Galceran, Yuk-Luen Chan, Neville Rapp, Kevin J. Martin, and Eduardo Slatopolsky Renal Division, Department of Medicine, Washington University School of Medicine, St. Louis, Missouri 63110

\begin{abstract}
Hypocalcemia is the main factor responsible for the genesis of secondary hyperparathyroidism in chronic renal disease. Studies with parathyroid cells obtained from uremic patients indicate that there is a shift in the set point for calcium-regulated hormone (parathyroid hormone [PTH]) secretion. Studies were performed in dogs to further clarify this new potential mechanism. Hypocalcemia was prevented in uremic dogs by the administration of a high calcium diet. Initially, ionized calcium was $4.79 \pm 0.09$ $\mathrm{mg} / \mathrm{dl}$ and gradually increased up to $5.30 \pm 0.05 \mathrm{mg} / \mathrm{dl}$. Despite a moderate increase in ionized calcium, immunoreactive PTH (iPTH) increased from $64 \pm 7.7$ to $118 \pm 21 \mathrm{pg} / \mathrm{ml}$. Serum $1,25(\mathrm{OH})_{2} \mathrm{D}_{3}$ decreased from $25.4 \pm 3.8$ to $12.2 \pm 3.6 \mathrm{pg} / \mathrm{ml}$. Further studies were performed in two other groups of dogs. One group received 150-200 ng and the second group 75-100 $\mathrm{ng}$ of $1,25(\mathrm{OH})_{2} \mathrm{D}_{3}$ twice daily. The levels of $1,25(\mathrm{OH})_{2} \mathrm{D}_{3}$ increased from $32.8 \pm 3.5$ to a maximum of $69.6 \pm 4.4 \mathrm{pg} / \mathrm{ml}$. In the second group the levels of serum $1,25(\mathrm{OH})_{2} \mathrm{D}_{3}$ after nephrectomy remained normal during the study. Amino-terminal iPTH did not increase in either of the two groups treated with $1,25(\mathrm{OH})_{2} \mathrm{D}_{3}$. In summary, the dogs at no time developed hypocalcemia; however, there was an $84 \%$ increase in iPTH levels, suggesting that hypocalcemia, per se, may not be the only factor responsible for the genesis of secondary hyperparathyroidism.
\end{abstract}

\section{Introduction}

Secondary hyperparathyroidism with markedly elevated serum concentration levels of parathyroid hormone (PTH) ${ }^{1}$ is a wellestablished complication of renal insufficiency (1). Several factors have been implicated in the pathogenesis of this disease, such as abnormal vitamin D metabolism, phosphate retention, altered set point for calcium regulated PTH secretion, and impaired degradation of PTH by the kidney.

Altered vitamin D metabolism, observed in patients with advanced renal disease, produces a decrease in the synthesis of 1,25-dihydroxycolecalciferol $\left(1,25(\mathrm{OH})_{2} \mathrm{D}_{3}\right)$, the active metabolite of the vitamin D (2), which leads to impaired intestinal calcium absorption (3) and skeletal resistance to the calcemic action of PTH (4-6). More recent evidence suggest that the low

Address correspondence and reprint requests to Dr. Slatopolsky, Washington University School of Medicine, 4949 Barnes Hospital Plaza, Box 8129, St. Louis, Missouri 63110.

1. Abbreviations used in this paper: GFR, glomerular filtration rate; $\mathrm{PPTH}$, immunoreactive PTH; PTH, parathyroid hormone.

J. Clin. Invest.

(C) The American Society for Clinical Investigation, Inc.

$0021-9738 / 86 / 10 / 1097 / 06 \$ 1.00$

Volume 78, October 1986, 1097-1102 levels of $1,25(\mathrm{OH})_{2} \mathrm{D}_{3}$ may also play a role in the altered synthesis (7) and secretion (8-11) of PTH.

Phosphate retention plays an important role in the pathogenesis of secondary hyperparathyroidism. Studies from our laboratory $(12-14)$ and from other groups $(15,16)$ indicate that a reduction in phosphorus intake in chronic renal disease can prevent or improve secondary hyperparathyroidism. Hyperphosphatemia has been associated with a decrease in the activity of the enzyme 1-hydroxylase, which is responsible for the conversion of 25-hydroxyvitamin $\mathrm{D}_{3}\left(25(\mathrm{OH}) \mathrm{D}_{3}\right)$ to its active metabolite $1,25(\mathrm{OH})_{2} \mathrm{D}_{3}(17)$. In addition, hyperphosphatemia per se complexes serum calcium, further decreasing the level of ionized calcium.

The set point for calcium-regulated PTH secretion in hyperparathyroid states has been studied in detail $(18,19)$ in dispersed parathyroid cells. The results from these studies have demonstrated an increase in the set point for calcium to $1.2 \mathrm{mM}$ in hyperplastic parathyroid glands when they were compared with $1.03 \mathrm{mM}$ calcium in normal glands. Moreover, BellorinFont et al. (20) demonstrated that the adenylate cyclase of hyperplastic glands is less susceptible to inhibition by calcium, requiring under normal conditions $0.22-0.28 \mathrm{mM}$ ionized $\mathrm{Ca}^{++}$ for $50 \%$ inhibition, whereas comparable inhibition of the adenylate cyclase obtained from hyperplastic parathyroid glands was seen at $0.7-1.0 \mathrm{mM} \mathrm{Ca}^{++}$. Thus, it is possible that this alteration in the regulation of the adenylate cyclase plays an additional role in the abnormal secretion of PTH seen in uremia.

Previous studies from our laboratory in dogs and humans $(21,22)$ have demonstrated the importance of the kidney in the removal of immunoreactive PTH (iPTH) from the circulation. These studies suggest that the impaired degradation of iPTH may be a contributing factor to the markedly elevated serum concentration of $\mathrm{COOH}$-terminal iPTH seen in chronic renal insufficiency.

Regardless of the precise mechanism involved, it is well accepted that hypocalcemia is the main factor responsible for the genesis of secondary hyperparathyroidism. Recent evidence suggests that there is a shift in the set point for calcium-regulated PTH secretion (19) in studies in vitro with parathyroid cells obtained from uremic patients. Thus, a higher serum concentration of ionized calcium may be necessary to suppress the release of PTH. This study was designed to clarify this new concept, and to determine the effect of the administration of $1,25(\mathrm{OH})_{2} \mathrm{D}_{3}$ on PTH secretion in experimentally induced renal insufficiency in the dog.

\section{Methods}

We studied 17 healthy adult female mongrel dogs. After completion of baseline studies the animals were placed on special diets (Table I). 2 wk later, glomerular filtration rate (GFR) was reduced by $\sim 70 \%$ in all dogs by ligation of most of the branches of the left renal artery followed by contralateral nephrectomy, $10 \mathrm{~d}$ later (13). Both procedures were per- 
formed under general anesthesia. Catheters were implanted in the jugular vein and blood samples were obtained three times a day for 1 wk and then three times a week for $1 \mathrm{mo}$. The dogs were divided in three groups and the following protocols were followed.

\section{Experimental design}

Protocol 1. Six animals (Table I) were fed a high calcium diet providing $1.6 \%$ calcium $\left(6.4 \mathrm{~g} / \mathrm{d}\right.$ ), $0.95 \% \mathrm{PO}_{4}$, and $0.15 \% \mathrm{Mg}$ (High-Pro Dog Diet; Ralston Purina Co., St. Louis, MO). The diet was started 2 wk before the induction of renal failure and continued for 1 mo thereafter.

Protocol 2. Five dogs (Table I) were fed a normal calcium diet providing $0.80 \%$ calcium, $1.1 \% \mathrm{PO}_{4}$, and $\mathrm{Mg} 0.17 \%$ (50\% calcium-deficient diet powered (23) and 50\% High-Pro Dog Diet, Ralston Purina Co.). The diet was initiated $15 \mathrm{~d}$ before the induction of renal insufficiency and continued for $1 \mathrm{mo}$. Immediately before the right nephrectomy was performed, $200 \mathrm{ng}$ of $1,25(\mathrm{OH})_{2} \mathrm{D}_{3}$ was administered subcutaneously. For the next month, $150-200 \mathrm{ng}$ of $1,25(\mathrm{OH})_{2} \mathrm{D}_{3}$ was given orally twice a day.

Protocol 3. These studies were identical to those of protocol 2 except that the dose of $1,25(\mathrm{OH})_{2} \mathrm{D}_{3}$ was decreased to $75-100 \mathrm{ng}$ twice daily for $1 \mathrm{mo}$ (six dogs). At the end of the month the GFR was determined in each dog as described previously (13).

Analytical methods. Total serum calcium and magnesium were measured by atomic absorption spectrometry (model 503; Perkin-Elmer Corp., Instrument Div., Norwalk, CT). Serum-ionized calcium was measured by an ion-specific flow-through electrode (model SS20; Orion Research, Inc., Cambridge, MA). Serum phosphorus was measured by Auto-Analyzer II (Technicon Instruments, Tarrytown, NY). An aminoterminal PTH radioimmunoassay with exquisite sensitivity was developed to measure the biologically active region of PTH in normal and uremic animals. This was accomplished by a modification of synthetic hPTH 1-34 involving substitution of the $\mathrm{NH}_{2}$-terminal serine by tyrosine (Fig. 1). This resulted in the ability to produce a radioligand with much higher specific activity $(440-500 \mu \mathrm{Ci} / \mu \mathrm{g})$ than that of the unmodified peptide $(80-150 \mu \mathrm{Ci} / \mu \mathrm{g})$. The minimum detectable amount of hPTH 1-34 was $1 \mathrm{pg} /$ tube; sensitivity was well within the range found for biologically active PTH by bioassay. The curves obtained with the intact molecule, PTH 1-84, and the amino-terminal PTH 1-34 were parallel. The main circulating biologically active form of PTH in the dog was the intact peptide. Less than $5 \%$ of circulating PTH in uremic dogs was chromatographed in the region of the amino-terminal PTH 1-34. The normal circulating levels of amino-terminal PTH in the dog was $53.9 \pm 4.9 \mathrm{pg} /$ $\mathrm{ml}$ (range $20-80 \mathrm{pg} / \mathrm{ml}$ ). To determinate the effect on calcium on the secretion of PTH in normal dogs, a mild hypocalcemia (decrease in 0.3 $\mathrm{mg} / \mathrm{dl}$ ) was induced in six normal dogs by the administration of phosphorus intravenously. Amino-terminal PTH increased from 47.7 \pm 9.4 to $99.0 \pm 10.9 \mathrm{pg} / \mathrm{ml}$. PTH became undetectable when serum-ionized calcium was raised by $0.4-0.6 \mathrm{mg} / \mathrm{dl}$. The antibody was produced by injecting bovine PTH 1-34 to a rooster. The characteristics of this antibody (CH9N) has been fully described in a previous publication (21). All samples for each dog were determined by either duplicate or quadruplicate within the same assay. Plasma levels of $1,25(\mathrm{OH})_{2} \mathrm{D}_{3}$ were measured by the method developed by Reinhardt et al. (24). The lower limit of

Table I. Dietary Calcium, Phosphorus, Magnesium, and Creatinine Clearance in Three Study Protocols

\begin{tabular}{lllll}
\hline & \multicolumn{2}{l}{ Diet } & & \\
\cline { 2 - 4 } Protocol & $\mathrm{Ca}$ & $\mathrm{PO}_{4}$ & $\mathrm{Mg}$ & GFR \\
\hline & $\%$ & $\%$ & $\%$ & $\mathrm{ml} / \mathrm{min}$ \\
I & 1.6 & 0.95 & 0.15 & $17.0 \pm 2.4$ \\
II & 0.8 & 1.1 & 0.17 & $17.1 \pm 2.8$ \\
III & 0.8 & 1.1 & 0.17 & $17.6 \pm 2.9$
\end{tabular}
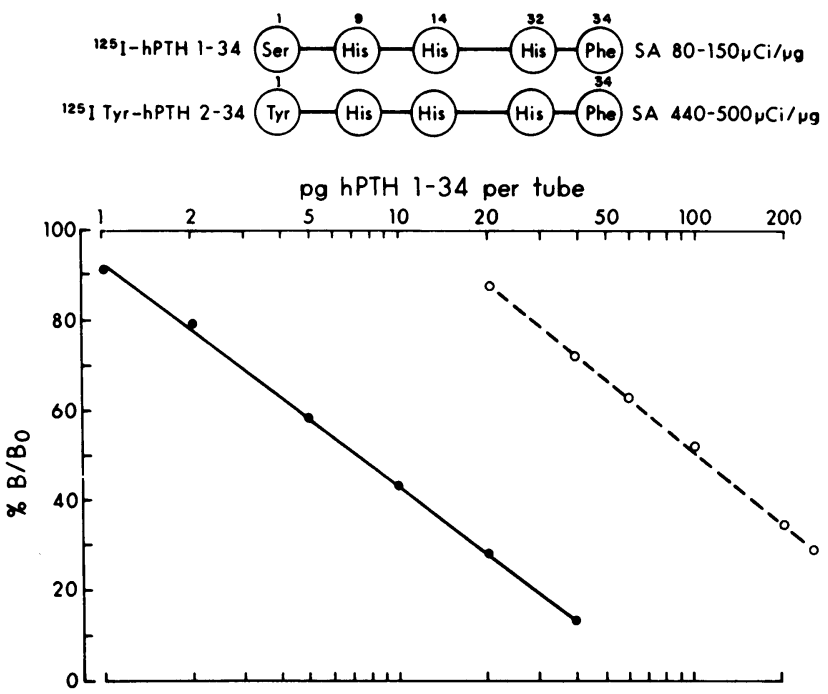

Figure 1. Effect of radioligand on the amino-terminal PTH radioimmunoassay. By replacing serine by tyrosine in the first amino acid, the specific activity of the radioligand could be increased from 80 to 150 $\mu \mathrm{Ci} / \mu \mathrm{g} \mathrm{(0)}$ to $440-550 \mu \mathrm{Ci} / \mu \mathrm{g}$ of protein (๑). This change in specific activity of the radioligand increased the sensitivity of the assay from $20 \mathrm{pg} /$ tube to $1 \mathrm{pg} /$ tube. $\mathrm{B} / \mathrm{B}_{0}$, ratio of $\mathrm{cpm}$ in presence of unlabeled antigen to cpm in precipitate without unlabeled antigen; SA, secondary hyperparathyroidism.

detection is $2 \mathrm{pg} /$ tube, and the range $18-40 \mathrm{pg} / \mathrm{ml}$, mean $26.4 \pm 9.31$ $\mathrm{pg} / \mathrm{ml}$.

\section{Results}

The experimental loss of renal function (Table I) was comparable in dogs given a high calcium diet, normal calcium diet plus 150$200 \mathrm{ng}$ of $1,25(\mathrm{OH})_{2} \mathrm{D}_{3}$ (orally, twice a day), and normal calcium diet plus $75-100 \mathrm{ng}$ of $1,25(\mathrm{OH})_{2} \mathrm{D}_{3}$ (orally, twice a day).

Fig. 2 shows the changes in serum creatinine, total calcium, and phosphorus in dogs fed a high calcium diet, before and after the development of renal insufficiency. Serum creatinine increased from $0.9 \pm 0.1$ to $2.6 \pm 0.25 \mathrm{mg} / \mathrm{dl}$. At the end of the studies, the mean glomerular filtration rate in the dogs was $17.0 \pm 2.4$ $\mathrm{ml} / \mathrm{min}$ (Table I) or a $70 \%$ reduction in renal function. Total serum calcium increased from $10 \pm 0.2$ to $11.2 \pm 0.1 \mathrm{mg} / \mathrm{dl}$ and remained constant during the entire month of the study. Serum phosphorus increased from $3.7 \pm 0.3$ to $5.2 \pm 0.45 \mathrm{mg} / \mathrm{dl}$ in the first week of the study, and thereafter reached a plateau $4.2 \pm 0.2$ $\mathrm{mg} / \mathrm{dl}$.

The temporal relationship between ionized calcium, the biologically active region of $\mathrm{PTH}$, and serum $1,25(\mathrm{OH})_{2} \mathrm{D}_{3}$ in dogs fed a high calcium diet are represented in the Fig. 3. Serumionized calcium remained constant during the early part of the study but tended to increase after the 1 st week, from $4.8 \pm 0.09$ $\mathrm{mg} / \mathrm{dl}$ to the highest peak of $5.3 \pm 0.05 \mathrm{mg} / \mathrm{dl}$. This increase was statistically significant $(P<0.005)$ from the 10 th $d$ to the end of the 3rd wk.

A progressive increase in the levels of amino-terminal PTH was observed in dogs fed a high calcium diet. The serum concentration of iPTH rose from $64.6 \pm 7.7 \mathrm{pg} / \mathrm{ml}$ at baseline to $83.8 \pm 11.7 \mathrm{pg} / \mathrm{ml}$ in the $2 \mathrm{nd}$ day of the study. After $1 \mathrm{wk}$ of renal insufficiency, iPTH increased by $\sim 84 \%(118 \pm 21 \mathrm{pg} / \mathrm{ml})$. Thus, 

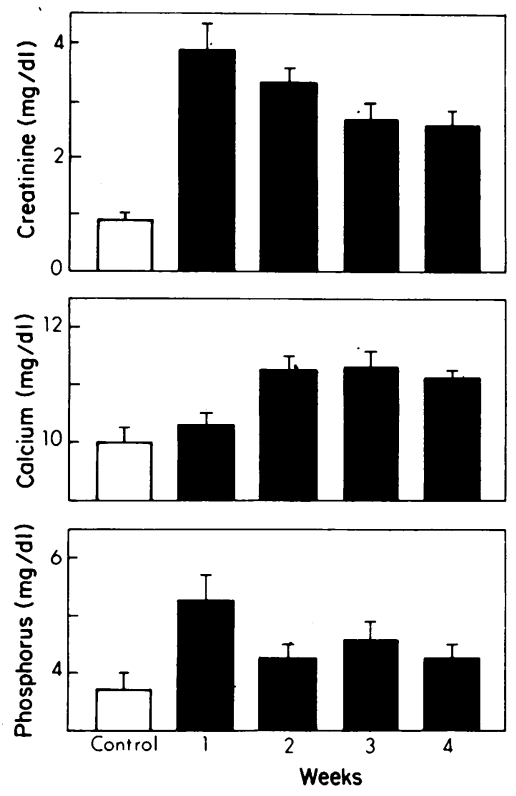

Figure 2. Serum creatinine, calcium, and phosphorus levels before and after renal insufficiency in a group of six dogs from protocol I.

in the absence of hypocalcemia, the dogs with experimental renal failure who were fed a high calcium diet increased their aminoterminal iPTH. The stable or increased ionized calcium and the increasing PTH levels, taken together, suggest defective regulation of PTH secretion at the parathyroid gland level. Before renal insufficiency, the levels of $1,25(\mathrm{OH})_{2} \mathrm{D}_{3}$ in serum averaged $25.4 \pm 3.8 \mathrm{pg} / \mathrm{ml}$, while after renal insufficiency was induced the serum levels of $1,25(\mathrm{OH})_{2} \mathrm{D}_{3}$ decreased to $12.2 \pm 3.6 \mathrm{pg} / \mathrm{ml}$. Since the dogs were fed a high calcium diet in spite of the reduction in $1,25(\mathrm{OH})_{2} \mathrm{D}_{3}$, serum-ionized calcium did not decrease. Thus, the decreased levels of $1,25(\mathrm{OH})_{2} \mathrm{D}_{3}$ did not contribute to hy-
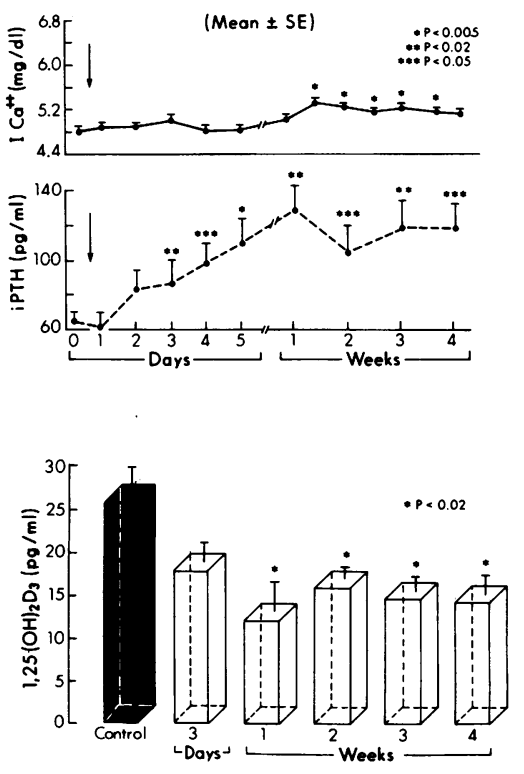

Figure 3. Serum-ionized calcium, amino iPTH levels, and serum $1,25(\mathrm{OH})_{2} \mathrm{D}_{3}$ before and after the induction of renal insufficiency (arrow) in a group of six dogs from protocol I. ICa, ionized calcium. perparathyroidism by reducing serum calcium. However, the low levels of $1,25(\mathrm{OH})_{2} \mathrm{D}_{3}$ potentially may have had an effect on the secretion of PTH independent of changes in ionized calcium.

To test this hypothesis, five dogs were studied. A similar protocol was followed, however they were fed a normal calcium diet and immediately before and after $5 / 6$ nephrectomy the animals received $150-200 \mathrm{ng}$ of $1,25(\mathrm{OH})_{2} \mathrm{D}_{3}$ twice daily, for the entire length of the study. The amount of calcium in the diet was decreased to prevent the development of severe hypercalcemia.

Fig. 4 represents the relationship between ionized calcium, the biologically active region of PTH, and circulating levels of $1,25(\mathrm{OH})_{2} \mathrm{D}_{3}$ when $1,25(\mathrm{OH})_{2} \mathrm{D}_{3}$ was administered to prevent the reduction in serum $1,25(\mathrm{OH})_{2} \mathrm{D}_{3}$ in dogs with renal insufficiency. Ionized calcium decreased from $5.1 \pm 0.12$ to $4.9 \pm 0.1$ $\mathrm{mg} / \mathrm{dl}$ on the 1st day. Ionized calcium was thereafter maintained within normal limits during the 1st week, but it tended to increase during the later part of the study. This difference was statistically significant $(P<0.005)$ from the 10th day to the end of the 3rd week. The middle part of the graph depicts the levels of the biologically active region of PTH before and after the induction of experimental renal insufficiency. Amino-terminal iPTH did not increase and remained within the normal range throughout the entire length of the study. In this group of uremic dogs, the
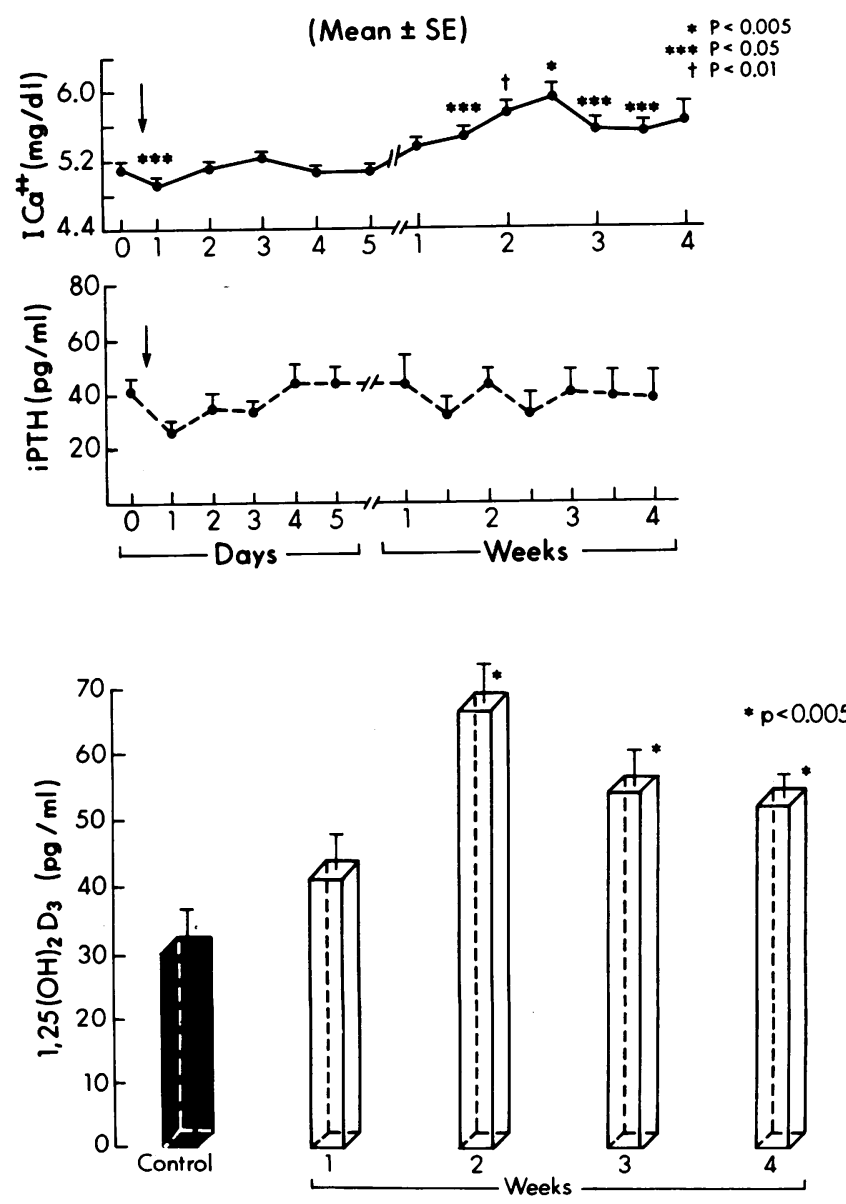

Figure 4. Serum-ionized calcium, amino iPTH levels, and serum $1,25(\mathrm{OH})_{2} \mathrm{D}_{3}$ in a group of five dogs from protocol II who received $150-200 \mathrm{ng}$ of $1,25(\mathrm{OH})_{2} \mathrm{D}_{3}$ twice daily, before and after the induction of renal insufficiency (arrow). ICa, ionized calcium. 
prevention of secondary hyperparathyroidism likely was not due to changes in the serum concentration of ionized calcium, since the same degree of hypercalcemia was observed in the first group (Fig. 3) when the dogs were fed a high calcium diet. The levels of $1,25(\mathrm{OH})_{2} \mathrm{D}_{3}$ increased from $32.8 \pm 3.5$ to $44.0 \pm 4.5 \mathrm{pg} / \mathrm{ml}$ at the end of the 1 st week, and $69.6 \pm 4.4 \mathrm{pg} / \mathrm{ml}$ at the end of the study. This increase was statistically significant $(P<0.005)$ from the 2nd to the 4th week of the study.

In an attempt to prevent mild hypercalcemia and to keep the levels of $1,25(\mathrm{OH})_{2} \mathrm{D}_{3}$ in a more physiological range, further studies were done in another group of six dogs (protocol 3) where the dose of $1,25(\mathrm{OH})_{2} \mathrm{D}_{3}$ was decreased from 150-200 $\mathrm{ng}$ twice daily to 75-100 ng twice daily. Fig. 5 illustrates the relationship between ionized calcium, the biologically active region of PTH, and circulating levels of $1,25(\mathrm{OH})_{2} \mathrm{D}_{3}$ in this group of six dogs. The serum levels of ionized calcium and amino-terminal iPTH remained within normal limits and did not change significantly throughout the study. The levels of $1,25(\mathrm{OH})_{2} \mathrm{D}_{3}$ remained within the normal range with a maximum value of $36.5 \pm 5.9$ $\mathrm{pg} / \mathrm{ml}$. This value is statistically significant and different from the one obtained $(69.6 \pm 4.4 \mathrm{pg} / \mathrm{ml})$ during the administration of $1,25(\mathrm{OH})_{2} \mathrm{D}_{3}$ at $150-200 \mathrm{ng}$ twice daily.

\section{DISCUSSION}

It is well established that secondary hyperparathyroidism appears early in the course of renal insufficiency. In general, as renal
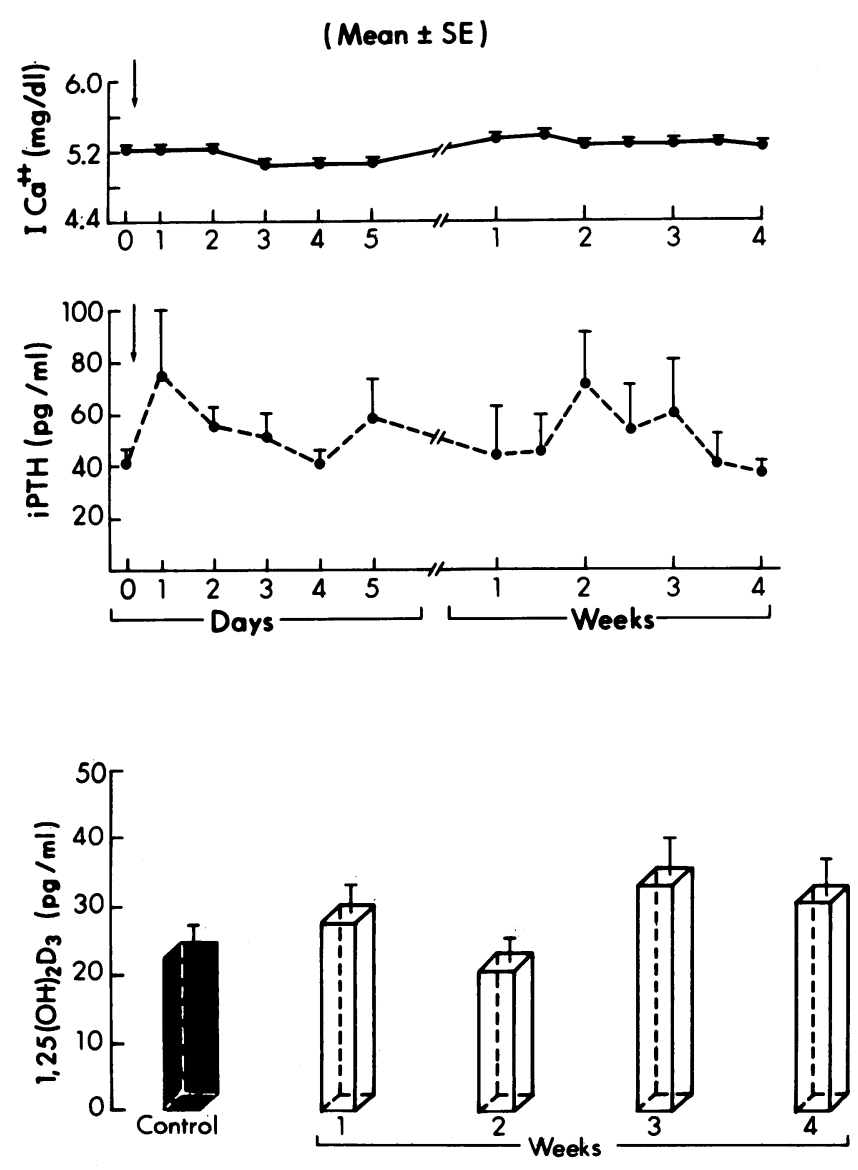

Figure 5. Serum-ionized calcium, amino iPTH levels, and serum $1,25(\mathrm{OH})_{2} \mathrm{D}_{3}$ in a group of six dogs from protocol III who received $75-100 \mathrm{ng}$ of $1,25(\mathrm{OH})_{2} \mathrm{D}_{3}$ twice daily before and after renal insuffciency (arrow). ICa, ionized calcium. insufficiency advances, a progressive increase in the serum concentration of iPTH is observed. It is generally accepted that transient and recurrent or sustained hypocalcemia is the main factor in the genesis of secondary hyperparathyroidism.

Brown et al $(18,19)$ demonstrated in uremic patients a shift in the set point for calcium-regulated PTH release in hyperplastic parathyroid glands. Adenylate cyclase from hyperfunctioning parathyroid glands (20) was less sensitive to inhibition by $\mathrm{Ca}^{++}$ when compared with the enzyme obtained from normal parathyroid glands. The decreased sensitivity of the adenylate cyclase of hyperplastic parathyroid glands to $\mathrm{Ca}^{++}$is, at least in part, a consequence of the increased affinity of the adenylate cycle system of hyperplastic glands for magnesium. Thus, a higher calcium concentration than normal seems necessary to suppress the abnormal secretion of PTH in chronic renal insufficiency.

In our experimental model, the hypocalcemia was prevented by the administration of a high calcium diet. The animals at no time developed hypocalcemia (Fig. 3); moreover, ionized calcium had a tendency to increase during the 2nd week. However, amino-terminal PTH (Fig. 3) increased above normal values by the 2nd day of the study and at the end of the study iPTH had increased by $\sim 84 \%$. Thus, the constant or elevated circulating levels of ionized calcium were unable to prevent the increasing concentrations of iPTH. Similar results have been demonstrated in ponies (25) and in dogs (26). In both studies, a significant increase in the concentration of total serum calcium, constant levels of ionized calcium (25), and a significant increase in the concentration of iPTH was observed after bilateral nephrectomy. The stable or increased ionized calcium and the increasing PTH levels taken together suggest defective regulation of PTH secretion at the parathyroid gland level.

Several investigators have provided evidence that vitamin D metabolites, in particular $1,25(\mathrm{OH})_{2} \mathrm{D}_{3}$, have a direct effect on the regulation of PTH synthesis and secretion. Studies in vitro have demonstrated a calcium-binding protein from porcine parathyroid gland (27) and specific binding of $1,25(\mathrm{OH})_{2} \mathrm{D}_{3}$ to nuclear and cytosolic receptors in normal porcine parathyroid gland (28) and in human parathyroid adenoma (29). The administration of ${ }^{3} \mathrm{H}-1,25(\mathrm{OH})_{2} \mathrm{D}_{3}$ to vitamin D-deficient chicks showed a much higher concentration of the radioactive material in the parathyroid glands and the intestine than in blood (30). Chertow et al. (31) and Au and Bukowsky (32) demonstrated an inhibitory effect of $1,25(\mathrm{OH})_{2} \mathrm{D}_{3}$ on PTH release in the rat. More recent studies (7) demonstrated that $1,25(\mathrm{OH})_{2} \mathrm{D}_{3}$ decreased steady state levels of prepro-PTH messenger RNA (mRNA) in a dose-dependent manner. This effect was first noted at $24 \mathrm{~h}$ after the administration of $1,25(\mathrm{OH})_{2} \mathrm{D}_{3}$ to cultured bovine parathyroid cells. Chan et al. (33) and Cantley et al. (34), working with monolayer cultures of bovine parathyroid cells, have clearly demonstrated that $1,25(\mathrm{OH})_{2} \mathrm{D}_{3}$ has an inhibitory effect on the release of PTH.

In vivo studies (35) have failed to show any acute effects of $1,25(\mathrm{OH})_{2} \mathrm{D}_{3}$ on PTH release. However, Oldham et al. (10) in vitamin $\mathrm{D}$-deficient dogs clearly showed that higher concentrations of $\mathrm{Ca}^{++}$were necessary to suppress PTH release, but when the same animals were pretreated with $1,25(\mathrm{OH})_{2} \mathrm{D}_{3}$ the parathyroid glands appeared more sensitive to mild increments in serum calcium. Slatopolsky et al. (11) showed a substantial decrease in iPTH levels with long-term intravenous administration of $1,25(\mathrm{OH})_{2} \mathrm{D}_{3}$ to uremic patients maintained on dialysis. After $1,25(\mathrm{OH})_{2} \mathrm{D}_{3}$ was discontinued, iPTH rose to pretreatment levels.

In the animals that received a high calcium intake we ob- 
served a decrease in the concentration of $1,25(\mathrm{OH})_{2} \mathrm{D}_{3}$ immediately after the experimental induction of renal insufficiency (Fig. 3). However, hyperparathyroidism developed, although serum calcium did not decrease. Thus, the low levels of $1,25(\mathrm{OH})_{2} \mathrm{D}_{3}$, independent of changes in ionized calcium, may have directly effected abnormal secretion of PTH. The absence of increasing levels of iPTH in the presence of normal or increased ionized calcium levels (Figs. 4 and 5, respectively) with the administration of two different doses of $1,25(\mathrm{OH})_{2} \mathrm{D}_{3}$ support this hypothesis. The doses of $1,25(\mathrm{OH})_{2} \mathrm{D}_{3}$ that we used were 75-100 or 150-200 ng twice a day; these are considered to be physiological or slightly pharmacological doses. In chronic renal insufficiency the parathyroid glands are hyperplastic. It is well accepted that these glands have a shift in the set point for calcium and an altered adenylate cyclase activity; both these mechanisms may be related to $1,25(\mathrm{OH})_{2} \mathrm{D}_{3}$. Since we avoided the fall in the serum concentration of $1,25(\mathrm{OH})_{2} \mathrm{D}_{3}$ by its exogenous administration, it is possible that with the early administration of this hormone we prevented the altered synthesis and secretion of iPTH associated to the low levels of $1,25(\mathrm{OH})_{2} \mathrm{D}_{3}$.

An interesting observation was seen in the group of dogs receiving $1,25(\mathrm{OH})_{2} \mathrm{D}_{3}, 150-200 \mathrm{ng}$ twice daily. Despite mild hypercalcemia and high levels of circulating $1,25(\mathrm{OH})_{2} \mathrm{D}_{3}$ serum iPTH did not become undetectable, suggesting that in uremic dogs, other factors beside calcium and $1,25(\mathrm{OH})_{2} \mathrm{D}_{3}$ may have a regulating effect on the secretion of PTH (36).

From the results obtained in this study, it is clear that hypocalcemia is not the only mechanism involved in the genesis of secondary hyperparathyroidism. Moreover, stable or increased levels of ionized calcium, as in this experimental model, do not suppress the abnormal secretion of iPTH. Therefore, it appears that other mechanisms are also involved in the abnormal secretion of PTH. These data suggest that low levels of $1,25(\mathrm{OH})_{2} \mathrm{D}_{3}$, independent of a fall in serum calcium, may contribute to altered regulation of PTH secretion by calcium in renal insufficiency. Potentially, alterations in cytosolic calcium due to abnormal calcium fluxes in parathyroid cells from patients or dogs with chronic renal failure may contribute to the altered secretion of PTH. Further studies are necessary to define the precise effects of phosphorus on the $1,25(\mathrm{OH})_{2} \mathrm{D}_{3}$-parathyroid axis in chronic renal disease (36).

\section{Acknowledgments}

The authors wish to show their appreciation to Dr. Irene Gray-Hruvosky from Abbott Laboratories, Chicago, IL for providing the $1,25(\mathrm{OH})_{2} \mathrm{D}_{3}$ for this study, to Dr. Ronald Horst for double checking values for serum $1,25(\mathrm{OH})_{2} \mathrm{D}_{3}$, and to Mrs. Patricia Shy for her assistance in the preparation of the manuscript.

This work was supported by U. S. Public Health Service National Institute of Arthritis, Diabetes, Digestive and Kidney Diseases grants AM-09976 and AM-07126. Dr. Lopez-Hilker's salary was supported in part by a grant from the National Kidney Foundation of Eastern Missouri and Metro East, Inc.

\section{References}

1. Coburn, J., and E. Slatopolsky. 1986. Vitamin D, PTH and Renal Osteodystrophy in The Kidney. B. Brenner and F. C. Rector, editors. W. B. Saunders, Philadelphia. 1657-1729.

2. Fraser, D. R., and E. Kodicek. 1970. Unique biosynthesis by kidney of a biologically active vitamin D metabolite. Nature (Lond.). 228:764766.
3. Coburn, J. W., D. L. Hartenbower, and S. G. Massry. 1973. Intestinal absorption of calcium and the effect of renal insufficiency. Kidney Int. 4:96-103.

4. Massry, S. G., R. Stein, J. Garty, A. I. Arieff, J. W. Coburn, A. W. Norman, and R. M. Friedler. 1976. Skeletal resistance to the calcemic action of parathyroid hormone in uremia: role of $1,25(\mathrm{OH})_{2} \mathrm{D}_{3}$. Kidney Int. 9:467-474.

5. Somerville, P. J., and M. Kaye. 1978. Resistance to parathyroid hormone in renal failure: role of vitamin D metabolites. Kidney Int. 14: 245-254.

6. Massry, S. G., S. Tuma, S. Dua, and D. A. Goldstein. 1979. Reversal of skeletal resistance to parathyroid hormone in uremia by vitamin D metabolites. J. Lab. Clin. Med. 94:152-157.

7. Silver, J., J. Russell, and L. M. Sherwood. 1985. Regulation by vitamin D metabolites of messenger ribonucleic acid for preproparathyroid hormone in isolated bovine parathyroid cells. Proc. Natl. Acad. Sci. USA. 82:4270-4273.

8. Dietel, M., G. Dorn, R. Montz, and E. Altenahr. 1979. Influence of vitamin $\mathrm{D}_{3}, 1,25(\mathrm{OH})_{2} \mathrm{D}_{3}$ on parathyroid hormone secretion, adenosin 3', 5' monophosphate release, and ultrastructure of parathyroid glands in organ culture. Endocrinology. 105:237-245.

9. Madsen, S., K. Olgaard, and J. Ladefoged. 1981. Suppressive effect of $1,25(\mathrm{OH})_{2} \mathrm{D}_{3}$ on circulating parathyroid hormone in acute renal failure. J. Clin. Endocrinol. Metab. 53:823-827.

10. Oldham, S. B., R. Smith, D. L. Hartenbower, H. L. Hemry, A. W. Norman, and J. W. Coburn. 1979. The acute effects of 1,25dihydroxicolecalciferol on serum immunoreactive parathyroid hormone in the dog. Endocrinology. 104:248-254.

11. Slatopolsky, E., C. Weerts, J. Thielan, R. Horst, H. Harter, and K. J. Martin. 1984. Marked suppression of secondary hyperparathyroidism by intravenous administration of 1,25-dihydroxycholecalciferol in uremic patients. J. Clin. Invest. 74:2136-2143.

12. Slatopolsky, E., S. Caglar, L. Gradowska, J. Canterbury, E. Reiss, and N. S. Bricker. 1972. On the prevention of secondary hyperparathyroidism in experimental chronic renal disease using "proportional reduction" of dietary phosphorus intake. Kidney Int. 2:147-151.

13. Slatopolsky, E., S. Caglar, J. P. Pennell, D. D. Taggart, J. M. Canterbury, E. Reiss, and N. S. Bricker. 1971. On the pathogenesis of hyper-hyperparthyroidism in chronic experimental insufficiency in the dog. J. Clin. Invest. 50:492-499.

14. Rutherford, W. E., P. Bordier, P. Marie, K. Kruska, H. Harter, A. Greenwalt, J. Blondin, J. Haddad, N. Bricker, and E. Slatopolsky. 1977. Phosphate control and 25-hydroxycholecalciferol administration in preventing experimental renal osteodystrophy in the dog. J. Clin. Invest. 60:332-341.

15. Portale, A. A., B. E. Booth, B. P. Halloran, and C. Morris, Jr. 1984. Effect of dietary phosphorus on circulating concentrations of 1,25 dihydroxyvitamin $\mathrm{D}$ and immunoreactive parathyroid hormone in children with moderate renal insufficiency. J. Clin. Invest. 73:1580-1589.

16. Llach, F., and S. G. Massry. 1985. On the mechanism of secondary hyperparathyroidism in moderate renal insufficiency. J. Clin. Endocrinol. Metab. 61:601-606.

17. Tanaka, Y., and H. F. DeLuca. 1973. The control of vitamin D by inorganic phosphorus. Arch. Biochem. Biophys. 154:566-570.

18. Brown, E. M., M. F. Brennan, S. Hurwitz, R. Windeck, S. J. Marx, Am. M. Spiegel, J. O. Koehler, D. G. Gardner, and G. D. Aurbach. 1978. Dispersed cell prepared from human parathyroid glands: distinct calcium sensitivity of adenomas vs primary hyperplasia. J. Clin. Endocrinol. Metab. 46:267-275.

19. Brown, E. M., R. E. Wilkson, R. C. Eastman, J. Pallotta, and S. P. Marynick. 1982. Abnormal regulation of parathyroid hormone release by calcium in secondary hyperparathyroidism due to chronic renal failure. Clin. Endocrinol. Metab. 54:172-179.

20. Bellorin-Font, E., K. J. Martin, J. J. Freitag, C. Anderson, G. Sicard, E. Slatopolsky, and S. Klahr. 1981. Altered adenylate cyclase kinetics in hyperfunctioning human parathyroid glands. J. Clin. Endocrinol. Metab. 52:499-507.

21. Hruska, K. A., R. Kopelman, W. E. Rutherford, S. Klahr, and 
E. Slatopolsky. 1975. Metabolism of immunoreactive parathyroid hormone in the dog. The role of the kidney and the effects of chronic renal disease. J. Clin. Invest. 56:39-48.

22. Freitag, J., K. J. Martin, K. A. Hurska, C. Anderson, M. Conrades, J. Ladenson, S. Klahr, and E. Slatopolsky. 1978. Impaired parathyroid hormone metabolism in patients with chronic renal failure. $N$. Engl. J. Med. 298:29-32.

23. Kenny, A. D., and P. L. Munson. 1959. A method for biological assay of phosphatemic activity in parathyroid extracts. Endocrinology. 64:513-521.

24. Reinhardt, T. A., R. L. Horst, J. W. Orf, and B. W. Hollis. 1984. A microassay for 1,25-dihydroxyvitamin $D$ not requiring high performance liquid chromatography: application to clinical studies. J. Clin. Endocrinol. Metab. 58:91-98.

25. Tennant, B., J. E. Lowe, and J. B. Tasker. 1981. Hypercalcemia and hypophosphatemia in ponies following bilateral nephrectomy. Proc. Soc. Exp. Biol. Med. 167:365-368.

26. Tuma, S. N., and L. E. Mallette. 1983. Hypercalcemia after nephrectomy in the dog: role of the kidney and the parathyroid glands. $J$. Lab. Clin. Med. 102:213-219.

27. Oldham, S. B., J. A. Fisher, L. H. Shen, and C. D. Arnaud. 1974. Isolation and properties of a calcium binding protein from porcine parathyroid glands. Biochemistry. 13:4790-4796.

28. Cloix, J. F., A. Ulmann, M. Bachelet, and J. L. Funck-Brentano. 1976. Cholecalciferol metabolites binding in porcine parathyroid glands. Steroids. 28:743-751.

29. Haddad, J. G., J. Walgate, C. Min, and T. J. Hahn. 1976. Vitamin
D metabolite-binding proteins in human tissue. Biochim. Biophys. Acta. 444:921-925.

30. Henry, H. L., and A. W. Norman. 1975. Studies on the mechanism of action of calciferol. VII. Localization of 1,25-dihydroxy-vitamin $\mathrm{D}_{3}$ in chick parathyroid glands. Biochem. Biophys. Res. Commun. 62: 781-788.

31. Chertow, B. S., D. J. Baylink, J. E. Wergedal, M. H. H. Su, and A. W. Norman. 1975. Decrease in serum immunoreactive parathyroid hormone in rats and in parathyroid hormone secretion in vivo by 1,25 dihydroxycholecalciferol. J. Clin. Invest. 56:668-678.

32. Au, W. Y. W., and A. Bukowski. 1976. Inhibition of parathyroid hormone secretion by vitamin D metabolites in organ cultures of rat parathyroids. Fed. Proc. 35:530.

33. Chan, Y. L., C. McKay, E. Dye, and E. Slatopolsky. 1986. The effect of 1,25-dihydroxicolecalciferol on parathyroid hormone secretion by monolayer cultures of bovine parathyroid cells. Calcif. Tissue Int. 38:27-32.

34. Cantley, L. K., J. Russell, D. Lettieri, and L. M. Sherwood. 1985. 1,25-dihydroxyvitamin $D_{3}$ suppresses parathyroid hormone secretion from parathyroid cells in tissue culture. Endocrinology. 117:2114-2119.

35. Llach, F. J., J. W. Coburn, A. S. Brickman, K. Kurokawa, A. W. Norman, J. M. Canterbury, and E. Reiss. 1977. Acute actions of 1,25-dihydroxyvitamin $D_{3}$ in normal man, effect on calcium and parathyroid status. J. Clin. Endocrinol. Metab. 44:1054-1060.

36. Lopez-Hilker, S., N. Rapp, K. Martin, and E. Slatopolsky. 1986. On the mechanism of the prevention of secondary hyperparathyroidism by phosphate restriction. Kidney Int. 29:164a. (Abstr.) 